\title{
Maternal and Sociodemographic Factors Influence the Consumption of Ultraprocessed and Minimally-Processed Foods in Pregnant Women
}

\section{Fatores maternos e sociodemográficos influenciam o consumo de alimentos ultraprocessados e minimamente processados em} gestantes

\author{
Monique Tavares Pereira1( ${ }^{10}$ Monica Cattafesta ${ }^{2(0)}$ Edson Theodoro dos Santos Neto ${ }^{2(1)}$ \\ Luciane Bresciani Salaroli ${ }^{1,2}$ \\ ${ }^{1}$ Graduate Program in Nutrition and Health, Department of \\ Integrated Health Education, Universidade Federal do Espírito Santo, \\ Vitória, ES, Brazil \\ ${ }^{2}$ Graduate Program in Collective Health, Universidade Federal do \\ Espírito Santo, Vitória, ES, Brazil

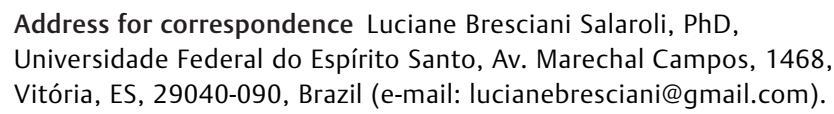

Rev Bras Ginecol Obstet 2020;42(7):380-389.

\begin{abstract}
Keywords

- feeding behavior

- dietary habits

- ultraprocessed foods

- pregnant

- maternal nutrition

Objective To analyze the consumption of minimally-processed and ultraprocessed foods in relation with sociodemographic variables, maternal habits, educational activity received during prenatal care and clinical history.

Methods A cross-sectional, analytical and descriptive study with 1,035 pregnant women who lives in the municipalities of the metropolitan region of Grande Vitória, Espírito Santo, Brazil (RMGV-ES), and who were hospitalized in establishments of the Unified Health System (SUS) due to childbirth (April-September 2010). The food frequency questionnaire, pregnant woman's card and information from the medical records of the health facility unit were analyzed. The Chi-square test and the binary logistic regression model were used to investigate the association between the independent variables and the consumption of ultraprocessed foods.

Results It was identified that pregnant women $\leq 19$ years of age were 2.9 times more likely to consume ultraprocessed foods (confidence interval [CI] 95\% 1.683-5.168, $p<0.001$ ), while those $\geq 35$ years old were less likely to consume them (odds ratio [OR] $0.265,95 \% \mathrm{Cl}$ $0.105-0.666, p=0.005)$. Maternal smoking increased the odds of consumption of ultraprocessed foods by 2.2 times $(95 \% \mathrm{Cl} 1.202-4.199, p=0.011)$ and pregnant women who did not obtain information on healthy food during prenatal care presented $54.1 \%$ less chances of consuming minimally-processed foods (OR 0.459, 95\% Cl 0.307-0.687, $p<0.001$ ).

Conclusion Smoking during the gestational period and being a teenager are factors that influence the consumption of ultraprocessed foods of pregnant women. Race/ color, head of household, age group, receiving of information about feeding in the prenatal period and not having smoked in gestation determined the consumption of minimally-processed foods.
\end{abstract}

received

December 22, 2019

accepted

April 23, 2020
DOI https://doi.org/

10.1055/s-0040-1712996. ISSN $0100-7203$.
Copyright $\odot 2020$ by Thieme Revinter

Publicações Ltda, Rio de Janeiro, Brazil
License terms

(c) 0 


\section{Resumo}

\section{Palavras-chave \\ - comportamento alimentar \\ - hábitos alimentares \\ - alimentos ultraprocessados \\ - gestante \\ - nutrição materna}

Objetivo Analisar o consumo de alimentos minimamente processados e ultraprocessados e a sua associação com variáveis sociodemográficas, hábitos maternos, atividade educacional recebida durante o pré-natal e histórico clínico.

Métodos Estudo transversal, analítico e descritivo com 1.035 gestantes que moram nos municípios da Região Metropolitana da Grande Vitória, Espírito Santo, Brasil (RMGV-ES), e que foram internadas em estabelecimentos do Sistema Único de Saúde (SUS) devido ao parto (abril-setembro de 2010). Foram analisados o questionário de frequência alimentar, o cartão da gestante e as informações dos prontuários da unidade de saúde. O teste do Quiquadrado e o modelo de regressão logística binária foram utilizados para investigar a associação entre as variáveis independentes e o hábito alimentar.

Resultados Identificou-se que as gestantes com idade $\leq 19$ anos tinham 2,9 vezes mais chances de consumirem alimentos ultraprocessados (intervalo de confiança [IC] 95\% 1,683-5,168; $p<0,001)$, enquanto aquelas com $\geq 35$ anos tinham menos chances de consumí-los (razão de chances [RC] 0,265; IC 95\% 0,105-0,666; $p=0,005)$. O tabagismo materno aumentou as chances de consumo de alimentos ultraprocessados em 2,2 vezes (IC95\% 1,202-4,199; $p=0,011$ ) e as gestantes que não receberam orientações sobre alimentação saudável durante o pré-natal apresentaram $54,1 \%$ menos chances de consumirem alimentos minimamente processados ( RC 0,459; IC95\% 0,307-0,687; $p<0,001)$.

Conclusão Fumar durante o período gestacional e ser adolescente são fatores que influenciam o consumo de alimentos ultraprocessados em gestantes. Raça/cor, chefe da família, faixa etária, recebimento de informações sobre alimentação no pré-natal e não fumar na gestação determinaram o consumo de minimamente processados.

\section{Introduction}

Major changes have occurred in the dietary patterns of the population in recent years, mainly in relation to the substitution of nutrient-rich in natura foods for industrialized foods with high energy density and low nutritional quality. ${ }^{1}$ Factors such as the search for practicality and absence of time have led to various social changes and changes in health and food consumption of the population. ${ }^{2}$ Given the scenario of modification of food patterns and changes in the forms of food and beverage processing, Monteiro et al. (2016) ${ }^{3}$ proposed a new system for food classification. For this new classification, food items were grouped according to the extent and purpose of processing. Titled NOVA, consumption items are classified into four categories: in natura or minimally-processed foods; processed culinary ingredients; processed foods and ultraprocessed foods. ${ }^{3}$ The presence of ultraprocessed foods in the food consumption of Brazilians has been gradually expanding, with the need for a deep investigation of their impact on the health of the population. $^{3,4}$ Although there is a trend of high intake of ultraprocessed foods at all stages of the life cycle, ${ }^{5,6}$ it is during gestation that women are more likely to change their pattern of food consumption due to concern about their maternal responsiveness. ${ }^{7}$ Thus, we analyzed the consumption of minimally-processed and ultraprocessed foods in relation with sociodemographic factors, maternal habits, educational activities and clinical history of pregnant women during prenatal care.

\section{Methods}

This is a cross-sectional, analytical and descriptive study, with data collected from April to September 2010. The data of the present study are part of a larger study titled "Evaluation of the Quality of Prenatal Care in the Metropolitan Region of Grande Vitória, Espírito Santo, Brazil (RMGV-ES): Access and Integration of Health Services." 8 The sample consisted of pregnant women living in the municipalities of the metropolitan region of Grande Vitória, ES (MRGV-ES), hospitalized in establishments of the Unified Health System (SUS, in the Portuguese acronym) due to childbirth. This research was conducted in eight health facilities of the MRGV-ES, with these being contracted or belonging to the SUS. To calculate the sample size, we used the sample size formula to estimate a proportion of women studied. Through the data provided by the Information System on Live Births (SINASC, in the Portuguese acronym), a total of 17,980 live births were established in the public network or through the SUS, which number approximately reflects the number of pregnant women residing in the MRGV-ES. The indicator "Percentage of Live Births With by Seven or More Prenatal Care Consultations" was also considered, as an approximation of the utilization of health services during pregnancy. Considering a desired precision of 
$4 \%$, drawing effect equal to 1.5 and significance level of $5 \%$, calculations resulted in the sample size of 850 women. The total was increased by $\sim 30 \%$ to consider possible losses or refusals. A pilot study was performed with 67 parturients (not included in the study) in one of the establishments where the main study was conducted, for verification of the graphical presentations of the questionnaires, as well as the test on the understanding of their items and the evaluation of the average time of completion of the forms. All questions were tested by the Kappa, weighted Kappa and McNemar tests. These analyses demonstrated their applicability in the population studied, including questions about food consumption. The data were collected by a team through a closed structured interview, a full copy of the pregnant woman's card, and the retrieval of information from the medical records of the health facility where the delivery was performed. The interviewers visited at least once a week all eight maternity hospitals included in the study, approached women at the time after the birth, when they verified the possibility of the interview and possession of the pregnant woman's card. Women who did not have a pregnant woman's card were excluded, as well as those who underwent prenatal (all or part) follow-up in the private subsystem; pregnant women hospitalized with complications who did not have babies; and those who had followup in the municipalities outside the MRGV-ES. The women who had cesarean delivery had their data collected 12 hours after delivery, so that the anesthetic effects of the surgical procedure would not interfere with the responses. The race/ color variable was determined by autoclassification as white, black, or brown (brown/mulatto). In relation to age group, these were categorized as " $\leq 19$ years," "between 20 and 34 years," or " $\geq 35$ years," and the conjugal situation was categorized as "lives with partner" or "does not live with partner." The variable maternal occupation was classified as "paid work" for pregnant women who had some work with remuneration, and "without paid work," for those pregnant women who did not have paid work. In relation to the variable head of the family, these were categorized as "own," "companion," or "other." Socioeconomic classification was determined based on the criterion of Brazilian Economic Classification of the Brazilian Association of Research Companies. ${ }^{9}$ The pregnant women were classified as class $\mathrm{A} / \mathrm{B}, \mathrm{C} 1 / \mathrm{C} 2$, or $\mathrm{D} / \mathrm{E}$ to improve the description of the outcomes. The use of tobacco and alcohol during pregnancy was analyzed through questions with direct answers ("yes" or "no"). It was questioned whether during the prenatal period there was information about the advantages of healthy food and its importance for the prevention of children's health problems. This variable was dichotomized in "yes" or "no." The data on prenatal medical care were analyzed considering the number of prenatal consultations reported by the pregnant woman. This variable was classified as having performed from "one to five" or "six or more" prenatal visits. Fifteen food items registered through the questionnaire applied were evaluated. This questionnaire was based on the Vigilance System for Risk Factors for NonCommunicable Chronic Diseases of the Brazilian Ministry of Health (Vigitel, in the Portuguese acronym), which annually evaluates the food habits in Brazilian capitals. ${ }^{10}$ The frequency of reported intake was converted to daily frequency, so that all food items had the same unit. The daily frequency values were multiplied by the portion of each item consumed, thus revealing the number of servings consumed daily. ${ }^{11}$ After the calculation of the weight of the frequency of consumption of each item, the analyzed foods were inserted into groups established by the classification of foods based on the extent and purpose of their processing by NOVA. ${ }^{3}$ The foods were grouped according to the criteria proposed by Monteiro et al. $(2016)^{3}$ in the NOVA classification, which considers the characteristics of the purpose and extent of the industrial processing they have undergone: in natura or minimaly-processed, processed culinary ingredients, processed foods and ultraprocessed foods. For this study, the foods that were classified as minimally-processed and ultraprocessed were used. The Chi-square test was used to analyze the differences in proportions. The significance level of $\alpha<5 \%$ was adopted. The distribution of the consumption of minimally-processed and ultraprocessed foods was evaluated in quartiles. The binary logistic regression model was used to investigate the association between the independent variables and the consumption of minimallyprocessed foods and consumption of ultraprocessed foods. The variables included in the binary logistic regression analysis were selected according to the statistical significance in the Chi-square test $(p<0.2)$. The lowest quartile (Q1) and the highest quartile (Q4) were analyzed for the purpose of analyzing the extremes of consumption with the independent variables. All statistical analyzes were performed in the IBM SPSS Statistics for Windows, version 22.0 (IBM Corp., Armonk, NY, USA). This study was conducted according to the guidelines laid down in the Declaration of Helsinki, and all procedures involving human subjects were approved by Research Ethics Committee of the Health Sciences Center of Universidade Federal do Espírito Santo (grant number 3.060.797) and CAAE (grant number 99562818.0.0000.5060). Written informed consent was obtained from all subjects.

\section{Results}

The sociodemographic variables, maternal habits, educational activity and clinical history were analyzed according to the quartiles of minimally-processed food consumption of 1,035 pregnant women (-Table $\mathbf{1}$ ). The age group and the consumption of minimally-processed foods $(p=0.015)$ were associated, and it was observed that pregnant women aged $\leq 19$ years had lower consumption of minimally-processed foods $(32.8 \%, n=76)$ than the other age groups. Women $\geq 35$ years of age presented higher consumption of minimallyprocessed foods $(32.5 \%, n=26)$.

There was an association between maternal occupation ( $p=0.002)$ and consumption of minimally-processed foods, in which it was possible to observe that pregnant women without paid work had a lower consumption of minimally-processed $(28.6 \%, n=212)$. On the other hand, women with paid work had a higher consumption of minimally-processed foods $(29.9 \%, n=88)$. 
Table 1 Sociodemographic variables, maternal habits, educational ctivity and clinical history according to the consumption of minimally-processed foods by pregnant women

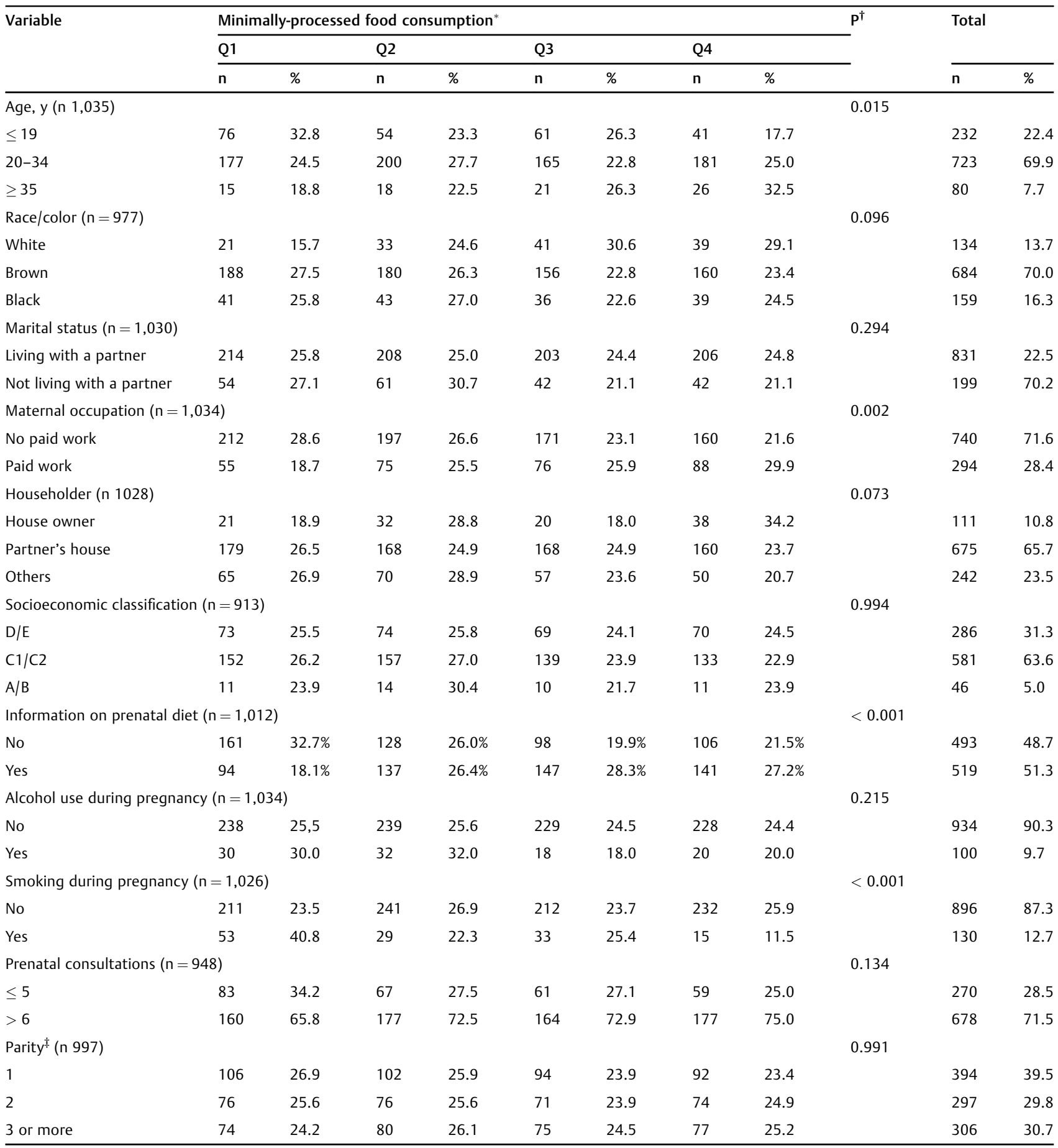

Abbreviations: Q1, first quartile; Q2, second quartile; Q3, third quartile; Q4, fourth quartile.

*The distribution of the consumption of foods was evaluated in quartiles.

${ }^{\dagger}$ The differences between quartiles were tested by the Chi-square test.

${ }^{\ddagger}$ Number of parturitions. 
384 Maternal and Sociodemographic Factors Influence the Consumption of Ultraprocessed Pereira et al.

Table 2 Sociodemographic variables, maternal habits, educational activity and clinical history according to consumption of ultraprocessed foods by pregnant women

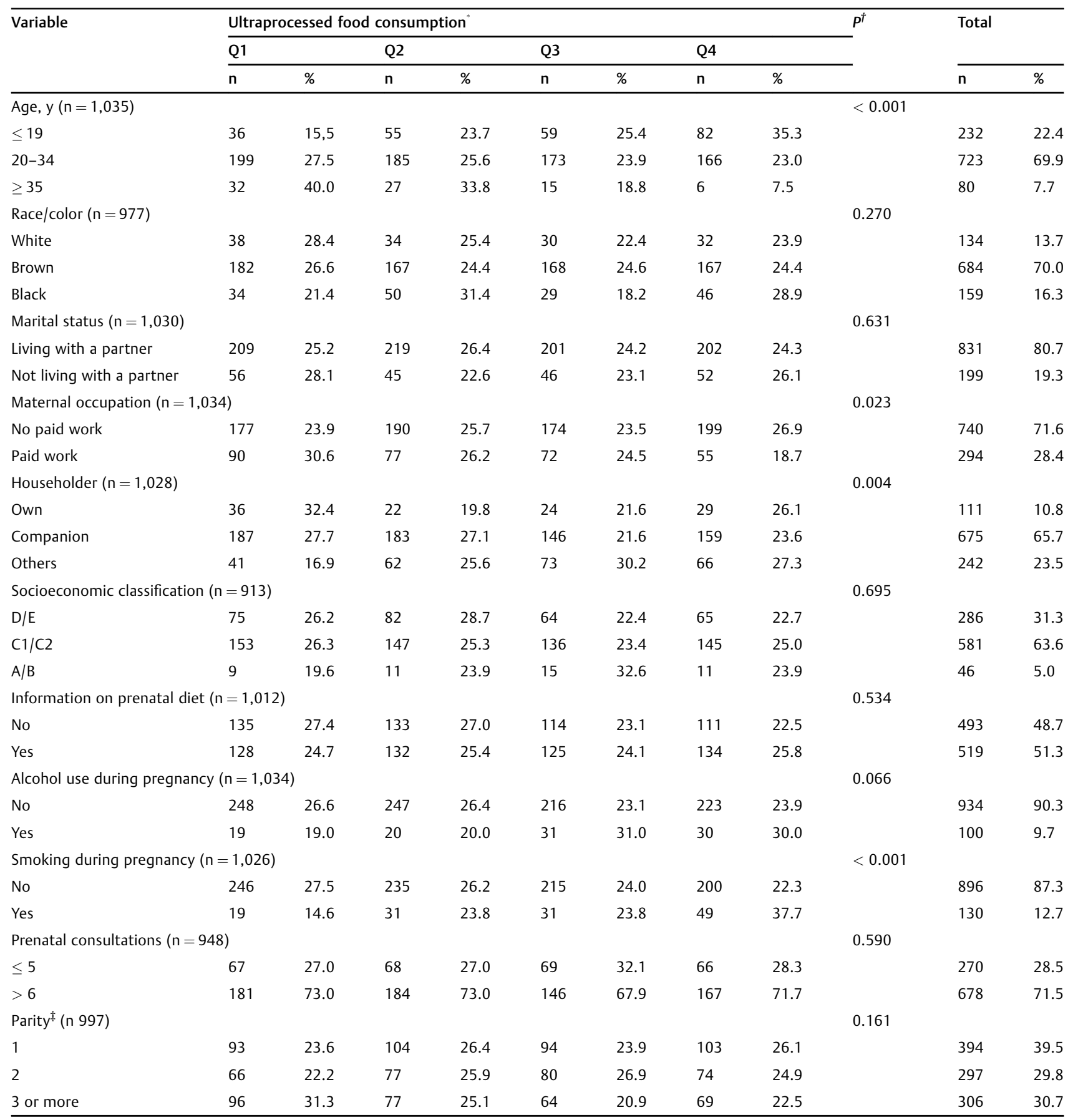

Abbreviations: Q1, first quartile; Q2, second quartile; Q3, third quartile; Q4, fourth quartile.

${ }^{*}$ The distribution of the consumption of foods was evaluated in quartiles.

${ }^{\dagger}$ The differences between quartiles were tested by the chi-square test.

${ }^{\ddagger}$ number of parturitions.

A statistical difference was identified in pregnant women who received information on healthy eating during prenatal care $(p<0.001)$ in relation to the consumption of minimallyprocessed foods, since women who did not receive information about food presented lower consumption of minimallyprocessed foods $(32.7 \%, n=161)$.
It was observed that pregnant women who smoked during pregnancy had lower consumption of minimallyprocessed foods $(p<0.001)$.

Regarding the analysis of sociodemographic variables, maternal habits, educational activity, and clinical history according to consumption of ultraprocessed foods ( - Table $\mathbf{2}$ ), there 
was a statistically significant association between age group $(p<0.001)$ and the consumption of ultraprocessed foods, with higher consumption of ultraprocessed foods among pregnant women age $\leq 19$ years, and lower consumption of ultraprocessed foods among women in the age group of $\geq 35$ years.

When evaluating the variables maternal occupation and head of the family, it was possible to identify an association with ultraprocessed food consumption, showing that women with paid work had lower ultraprocessed foods consumption, and women with unpaid work had higher consumption of ultraprocessed foods $(p=0.023)$. The pregnant women who were head of the family showed lower consumption of ultraprocessed foods ( $p=0.004)$.

Women who smoked during pregnancy $(37.7 \%, n=49)$ had a statistically significant association with the highest quartile of ultraprocessed food consumption $(p<0.001)$.

Binary logistic regression analyses showed that pregnant women $\leq 19$ years of age were 2.9 times more likely to consume ultraprocessed foods (odds ratio [OR]2.950, confidence interval
[CI] 95\% 1.683-5.168, $p<0.001$ ), while those $\geq 35$ years of age had less chance to consume them (OR 0.265, 95\% CI $0.105-0.666, p=0.005)$. Smoking during pregnancy increased the chance of consumption of ultraprocessed foods by 2.2 times (OR 2.247, 95\% CI 1.202-4.199, $p=0.011$ ) (-Table 3).

As for the consumption of minimally-processed foods (-Table 4), pregnant women aged $\leq 19$ years were $45.3 \%$ less likely than pregnant women aged 20 to 34 to consume these foods (OR 0.547, 95\% CI 0.324-0.923, $p=0.024$ ). Brown-skinned women were $57.8 \%$ less likely to consume minimally-processed foods than white-skinned ones (OR 0.466, 95\% CI 0.226-0.803, $p=0.008$ ).

Pregnant women who had the family headed by their partners were $56.8 \%$ less likely to consume minimallyprocessed foods than pregnant women who were the head of the family (OR 0.432, 95\% CI 0.217-0.859, $p=0.017$ ). However, women who received information on healthy food during prenatal care presented 2.17 times more chances to consume minimally-processed foods (OR 2.177, 95\% CI 1.455-3.257, $p=0.001$ ).

Table 3 Binary logistic regression analysis between consumption of ultraprocessed foods and associated variables in pregnant women

\begin{tabular}{|c|c|c|c|c|c|c|c|c|}
\hline \multirow[t]{4}{*}{ Variable } & \multicolumn{8}{|c|}{ Ultraprocessed food consumption } \\
\hline & \multicolumn{4}{|c|}{ Gross values } & \multicolumn{4}{|c|}{ Adjusted values } \\
\hline & \multirow[t]{2}{*}{$\overline{\mathrm{P}^{\mathrm{a}}}$} & \multirow[t]{2}{*}{ OR $^{*}$} & \multicolumn{2}{|l|}{$\mathrm{Cl}$} & \multirow[t]{2}{*}{$\mathrm{P}^{\mathrm{a}}$} & \multirow[t]{2}{*}{ OR $^{*}$} & \multicolumn{2}{|l|}{$\mathrm{Cl}$} \\
\hline & & & LL 95\% & UL $95 \%$ & & & LL 95\% & UL $95 \%$ \\
\hline \multicolumn{9}{|l|}{ Age, y } \\
\hline $20-34$ & & 1 & & & & 1 & & \\
\hline$\leq 19$ & $<0.001$ & 2.731 & 1.754 & 4.251 & $<0.001$ & 2.95 & 1.683 & 5.168 \\
\hline$\geq 35$ & 0.001 & 0.225 & 0.092 & 0.551 & 0.005 & 0.265 & 0.105 & 0.666 \\
\hline \multicolumn{9}{|c|}{ Maternal occupation } \\
\hline No paid work & & 1 & & & & 1 & & \\
\hline Paid work & 0.002 & 0.544 & 0.367 & 0.804 & 0.225 & 0.762 & 0.491 & 1.182 \\
\hline \multicolumn{9}{|l|}{ Householder } \\
\hline Own & & 1 & & & & 1 & & \\
\hline Companion & 0.842 & 1.056 & 0.62 & 1.798 & 0.98 & 0.992 & 0.543 & 1.814 \\
\hline Others & 0.03 & 1.998 & 1.069 & 3.735 & 0.243 & 1.543 & 0.745 & 3.194 \\
\hline \multicolumn{9}{|c|}{ Alcohol use during pregnancy } \\
\hline No & & 1 & & & & 1 & & \\
\hline Yes & 0.067 & 1.756 & 0.9613 & 3.2074 & 0.298 & 1.480 & 0.708 & 3.092 \\
\hline \multicolumn{9}{|c|}{ Smoking during pregnancy } \\
\hline No & & 1 & & & & 1 & & \\
\hline Yes & $<0.001$ & 3.1721 & 1.809 & 5.5622 & 0.011 & 2.247 & 1.202 & 4.199 \\
\hline \multicolumn{9}{|l|}{ Parity } \\
\hline 1 & & 1 & & & & 1 & & \\
\hline 2 & 0.956 & 1.012 & 0.656 & 1.563 & 0.089 & 1.548 & 0.935 & 2.563 \\
\hline 3 or more & 0.042 & 0.649 & 0.427 & 0.985 & 0.562 & 1.170 & 0.689 & 1.987 \\
\hline
\end{tabular}

Abbreviations: $\mathrm{Cl}$, confidence interval; LL, lower limit; OR, odds ratio; UL, upper limit. ${ }^{\text {a }}$ Statistical significance $\leq 0.2 \%$ in the Chi-square test were included in the analysis.

${ }^{*}$ ORs were adjusted to the other variables using binary logistic regression with $95 \% \mathrm{Cls}$. 
Table 4 Binary logistic regression analysis between consumption of minimally-processed foods and associated variables in pregnant women

\begin{tabular}{|c|c|c|c|c|c|c|c|c|}
\hline \multirow[t]{4}{*}{ Variable } & \multicolumn{8}{|c|}{ Minimally-processed food consumption } \\
\hline & \multicolumn{4}{|c|}{ Gross values } & \multicolumn{4}{|c|}{ Adjusted values } \\
\hline & \multirow[t]{2}{*}{$\overline{P^{a}}$} & \multirow[t]{2}{*}{$\mathrm{OR}^{*}$} & \multicolumn{2}{|l|}{$\mathrm{Cl}$} & \multirow[t]{2}{*}{$P^{a}$} & \multirow[t]{2}{*}{$\mathrm{OR}^{*}$} & \multicolumn{2}{|l|}{$\mathrm{Cl}$} \\
\hline & & & LL 95\% & UL 95\% & & & LL 95\% & UL 95\% \\
\hline \multicolumn{9}{|l|}{ Age, y } \\
\hline $20-34$ & & 1 & & & & 1 & & \\
\hline$\leq 19$ & 0.004 & 0.528 & 0.342 & 0.813 & 0.024 & 0.547 & 0.324 & 0.923 \\
\hline$\geq 35$ & 0.122 & 1.695 & 0.869 & 3.307 & 0.388 & 1.411 & 0.646 & 3.081 \\
\hline \multicolumn{9}{|l|}{ Race/color } \\
\hline White & & 1 & & & & 1 & & \\
\hline Brown & 0.007 & 0.458 & 0.259 & 0.811 & 0.008 & 0.426 & 0.226 & 0.803 \\
\hline Black & 0.057 & 0.512 & 0.257 & 1.019 & 0.053 & 0.469 & 0.217 & 1.011 \\
\hline \multicolumn{9}{|l|}{ Marital status } \\
\hline Living with a partner & & 1 & & & & 1 & & \\
\hline Not living with a partner & 0.349 & 0.808 & 0.517 & 1.263 & 0.273 & 0.749 & 0.447 & 1.256 \\
\hline \multicolumn{9}{|l|}{ Maternal occupation } \\
\hline No paid work & & 1 & & & & 1 & & \\
\hline Paid work & $<0.001$ & 2.12 & 1.429 & 3.145 & 0.281 & 1.295 & 0.809 & 2.072 \\
\hline \multicolumn{9}{|l|}{ Householder } \\
\hline Own & & 1 & & & & 1 & & \\
\hline Companion & 0.016 & 0.494 & 0.278 & 0.877 & 0.017 & 0.432 & 0.217 & 0.859 \\
\hline Others & 0.01 & 0.425 & 0.222 & 0.813 & 0.125 & 0.544 & 0.25 & 1.184 \\
\hline \multicolumn{9}{|c|}{ Information on prenatal feeding } \\
\hline No & & 1 & & & & 1 & & \\
\hline Yes & $<0.001$ & 2.278 & 1.593 & 3.259 & $<0.001$ & 2.177 & 1.455 & 3.257 \\
\hline \multicolumn{9}{|l|}{ Smoking during pregnancy } \\
\hline No & & 1 & & & & 1 & & \\
\hline Yes & $<0.001$ & 0.2574 & 0.1409 & 0.4703 & $<0.001$ & 0.269 & 0.132 & 0.545 \\
\hline \multicolumn{9}{|l|}{ Prenatal consultations } \\
\hline$<5$ & & 1 & & & & 1 & & \\
\hline$>6$ & 0.0287 & 1.5562 & 1.047 & 2.3132 & 0.1684 & 1.3771 & 0.8734 & 2.1713 \\
\hline
\end{tabular}

Abbreviations: $\mathrm{Cl}$, confidence interval; LL, lower limit; OR, odds ratio; UL, upper limit.

${ }^{a}$ Statistical significance $\leq 0.2 \%$ in the Chi-square test were included in the analysis.

${ }^{*}$ ORs were adjusted to the other variables using binary logistic regression with $95 \% \mathrm{Cls}$.

\section{Discussion}

The present study allowed identifying the factors associated with the consumption of ultraprocessed and minimallyprocessed foods. The data show that the consumption of ultraprocessed products diverged between the age groups, demonstrating a lower consumption of ultraprocessed foods among older women. This finding was similar to that in the study by Alves-Santos et al. ${ }^{12}$ in which older women showed a lower intake of ultraprocessed foods than the younger ones, indicating the age factor as strongly associated with the consumption of minimally-processed foods. It is still consistent with the findings by McGowan and McAuliffe, ${ }^{13}$ in which older women tend to adhere to a "healthy conscience" pattern, consisting mainly of higher intakes of whole-grain breads, fruits, vegetables, low-fat milk, and white meat, among others. This relationship can also be observed in Brazilian households, considering the 2008 to 2009 family budgets survey, conducted with individuals who were 10 years of age or older, which showed the consumption of ultraprocessed products tends to decrease as age increases. ${ }^{14}$

However, younger pregnant women presented high consumption of ultraprocessed foods, in agreement with the results already presented in the adolescent population of the city of Rio de Janeiro, in which pregnant women presented a high frequency of consumption of soft drinks, pizza, potato chips, and salty snacks, indicating food habit that is harmful to health. ${ }^{15}$ The association between high consumption of 
ultraprocessed products and age groups can also be found in non-pregnant women, in which adolescents consumed and spent more to purchase ultraprocessed foods, compromising the quality of their diet. ${ }^{16}$

The present study showed that maternal habits may interfere with food consumption. Women who reported having smoked during pregnancy were associated with higher consumption of ultraprocessed foods. Knowing that maternal smoking has a negative impact on the health of the mother and is related to a series of risk behaviors because it is associated with a greater chance of maternal and fetal intercurrences, ${ }^{17,18}$ it is important to offer pregnant women information about the effects of substances, which, in turn, will contribute to benefit obstetric outcomes. ${ }^{18}$ The impacts of maternal smoking on pregnancy outcomes are well documented and include predisposition to gestational diabetes, ${ }^{19}$ higher mortality and morbidity, ${ }^{20}$ and increased risk of preterm birth, and the consequences of cigarette smoking during pregnancy may accompany the baby throughout life. ${ }^{21}$ In addition, fetuses exposed to cigarette smoke during pregnancy tend to have a higher body mass index (BMI) in adulthood. $^{22}$

Other adverse outcomes associated with maternal smoking include congenital malformations, ${ }^{23,24}$ low birth weight $^{21,22}$ and restriction of intrauterine growth, ${ }^{20,25}$ suggesting that any newborn with significant exposure to smoking during gestation is likely to be adversely affected to some degree due to the chemical and toxic additives of tobacco. ${ }^{26}$ The present study has shown that pregnant women who presented a maternal habit of not smoking during the gestational period had a better habit of food consumption. In light of that, women who quit smoking before or during pregnancy can substantially reduce risks for themselves and their children. ${ }^{27}$

Sociodemographic factors were associated with the consumption of minimally-processed foods, specifically race/ skin color and being head of household. In a study of American women who were in the third trimester of pregnancy, it was shown that Black women tended to have higher caloric intake, consuming foods rich in fats, carbohydrates, and sugar and poor in important nutrients, such as folate and fiber. ${ }^{28}$

The head of household association and the consumption of healthier foods may demonstrate social inequalities, since female-headed households are largely associated with situations of economic vulnerability, in which women often end up in domestic activities and care of the offspring, which, in turn, results in greater difficulties to guarantee the subsistence of their own family, already with part-time affected generates dependency in low-paid jobs. ${ }^{29}$

Receiving information about healthy food during prenatal care was highlighted among women who had the highest consumption of minimally-processed foods, as recommended in the pregnant woman's booklet, which states that to have a healthy pregnancy the pregnant woman should seek to have a diet rich in natural foods and poor in processed foods, in favor of maternal well-being, growth, and adequate training of the fetus. ${ }^{30}$
Participants who did not receive information about healthy eating during the prenatal period had less chance of having healthier eating habits. Considering that such educational activities depend on health professionals, the challenge seems to be to understand the reasons why these behaviors are not being fully available to the target population. $^{31}$ The educator role played by the health professional during prenatal consultations is essential, since pregnant women should be instructed to adopt improvements or maintenance of healthy eating practices, making changes and/or creating new habits and, thus promoting a pregnancy free of future intercurrences. ${ }^{32}$ With these data, prenatal monitoring is identified as an important source of information that may contribute to excellent results in food consumption during pregnancy.

In the study done by Barros et al. ${ }^{15}$ it was verified that the adolescent pregnant women who received information about healthy eating during the prenatal period had better results in nutrient consumption. Verbeke and De Bourdeaudhuij $^{33}$ analyzed the eating behavior and nutritional choices of 148 pregnant women and 130 non-pregnant women and observed that pregnant women who followed nutritional recommendations made better eating choices than nonpregnant women. This corroborates the importance of prenatal follow-up, recognized as a relevant stage in the collection and perception of information, effectively contributing to improvements in the results of food consumption and gestation. $^{15}$

The limitations of the present study are related to the possibility of occurrence of recall bias, because the data was obtained through an interview, but this limitation may have been minimized by investigating the pregnant woman's medical chart and/or card. Still, the method used to collect data on eating habits may have involved underestimation; however, it made it possible to assess the consumption of the main food items evaluated in national surveys. Nevertheless, despite the limitations pointed out, the data presented here reflect the reality of the public and/or contracted establishments that performed the deliveries by the SUS of the MRGV-ES, and the design adopted enables assuming that the conclusions can be used in similar contexts.

It is also highlighted that it is the first study to investigate the association between maternal variables and educational activity received during prenatal care with ultraprocessed and minimally-processed consumption and, differently from other studies that analyzed isolated foods, in this study we used a classification that groups the foods according to purpose and extent of processing. ${ }^{3}$

Although this classification was recent and in the present study the fourth quartile was used to define the high consumption of a certain group, it allowed to classify in a satisfactory way those foods that belonged to the group that presented high amounts of sugars, saturated fat, trans fat, and low amount of fiber, characteristics that the literature shows belong to the ultraprocessed foods, which intensifies the risks for various diseases. ${ }^{1,3,34-36}$ 


\section{Conclusion}

The results of the present study suggest that being a pregnant adolescent and having smoked during pregnancy influence the increase in the consumption of ultraprocessed foods, which, consequently, can have an impact on the quality of the food choices of pregnant women.

The data also indicate that being an older pregnant woman, not being of brown skin color, being the head of the household, not having smoked cigarettes during pregnancy and having received information about healthy eating during prenatal care contribute to the better consumption of minimally-processed or in natura foods, thus offering better eating habits. It is necessary to evaluate the food consumption through these food groups, as it allows to identify the vulnerability of the population to food excesses, and thus to adapt and propose intervention measures that guarantee maternal and baby health. The present results point out that there is a need for the implementation of intervention measures in health service establishments with the objective of providing educational information and promoting healthy eating for mothers.

\section{Contributors}

Pereira M. T. contributed to conceptualization, data curation, formal analysis, investigation, methodology, resources, visualization, writing-original draft and writing-review \& editing. Cattafesta M. contributed to conceptualization, data curation, formal analysis, investigation, methodology, resources, supervision, validation, visualization, writing-original draft and writing-review \& editing. Santos Neto E. T. contributed to conceptualization, data curation, formal analysis, funding acquisition, investigation, methodology, project administration, resources, supervision, validation, visualization, writing-original draft and writing-review \& editing. Salaroli L. B. contributed to conceptualization, data curation, formal analysis, investigation, methodology, project administration, resources, supervision, validation, visualization, writingoriginal draft and writing-review \& editing.

\section{Conflict of Interests}

The authors have no conflict of interests to declare.

\section{Acknowledgments}

The authors would like to acknowledge all the Research Group in Epidemiology, Health and Nutrition (GEMNUT, in the Portuguese acronym). We gratefully acknowledge data from the "Evaluation of the Quality of Prenatal Care in the Metropolitan Area of Grande Vitória, Espírito Santo (RMGV-ES): Access and Integration of Health Services" project. The authors would like to thank the Foundation for Research Support of Espírito Santo/State Department of Health of Espírito Santo (FAPES, in the Portuguese acronym) and the Coordination for the Improvement of Higher Education Personnel (CAPES, in the Portuguese acronym). None of these funding agencies had any role in the design and conduct of the study.

\section{References}

1 Ministério da Saúde. Secretaria de Atenção à Saúde. Departamento de Atenção Básica [Internet]. [Food guide for the Brazilian population]. 2nd ed. Brasília (DF): Ministério da Saúde; 2014 [cited 2018 Mar 20]. Available from: http://bvsms.saude.gov.br/ bvs/publicacoes/guia_alimentar_populacao_brasileira_2ed.pdf

2 Popkin BM, Adair LS, Ng SW. Global nutrition transition and the pandemic of obesity in developing countries. Nutr Rev. 2012;70 (01):3-21. Doi: 10.1111/j.1753-4887.2011.00456.x

3 Monteiro CA, Cannon G, Levy RB, Moubarac JC, Jaime P, Martins AP, et al. NOVA. The star shines bright. World Nutr.. 2016;7(1-3): 28-38

4 Monteiro CA, Levy RB, Claro RM, Castro IRR, Cannon G. A new classification of foods based on the extent and purpose of their processing. Cad Saude Publica. 2010;26(11):2039-2049. Doi: 10.1590/S0102-311X2010001100005

5 Martins AP, Levy RB, Claro RM, Moubarac JC, Monteiro CA. Increased contribution of ultra-processed food products in the Brazilian diet (1987-2009). Rev Saude Publica. 2013;47(04): 656-665. Doi: 10.1590/S0034-8910.2013047004968

6 Devine CM, Bove CF, Olson CM. Continuity and change in women's weight orientations and lifestyle practices through pregnancy and the postpartum period: the influence of life course trajectories and transitional events. Soc Sci Med. 2000;50(04):567-582. Doi: 10.1016/s0277-9536(99)00314-7

7 Padmanabhan U, Summerbell CD, Heslehurst N. A qualitative study exploring pregnant women's weight-related attitudes and beliefs in UK: the BLOOM study. BMC Pregnancy Childbirth. 2015;15:99. Doi: 10.1186/s12884-015-0522-3

8 Santos Neto ET, Oliveira AE, Zandonade E, Gama SGN, Leal MdoC. [Prenatal patient cards and quality of prenatal care in public health services in Greater Metropolitan Vitória, Espírito Santo State, Brazil]. Cad Saude Publica. 2012;28(09):1650-1662. Doi: 10.1590/S0102-311X2012000900005

9 Associação Brasileira de Empresas de Pesquisa. [Economic Classification Criteria Brazil] [Internet]. 2003 [cited 2018 Jan 11]. Available from: http://www.abep.org/criterio-brasil

10 Ministério da Saúde. Secretaria de Vigilância em Saúde. Secretaria de Gestão Estratégica e Participativa [Internet]. [Vigitel Brazil 2009: surveillance of risk and protective factors for chronic diseases by telephone survey]. Brasília (DF): Ministério da Saúde; 2010 [cited 2020 Mar 10]. Available from: http://189.28.128.100/dab/docs/publicacoes/geral/publicacao_vigitel_2009.pdf

11 Cade J, Thompson R, Burley V, Warm D. Development, validation and utilisation of food-frequency questionnaires - a review. Public Health Nutr. 2002;5(04):567-587. Doi: 10.1079/PHN2001318

12 Alves-Santos NH, Eshriqui I, Franco-Sena AB, Cocate PG, FreitasVilela AA, Benaim C, et al. Dietary intake variations from preconception to gestational period according to the degree of industrial processing: A Brazilian cohort. Appetite. 2016; 105:164-171. Doi: 10.1016/j.appet.2016.05.027

13 McGowan CA, McAuliffe FM. Maternal dietary patterns and associated nutrient intakes during each trimester of pregnancy. Public Health Nutr. 2013;16(01):97-107. Doi: 10.1017/S1368980012000997

14 Instituto Brasileiro de Geografia e Estatística [Internet]. [Family budget survey 2008-2009: analysis of personal food consumption in Brazil]. Rio de Janeiro: IBGE; 2011 [cited 2018 Jun 13]. Available from: https://biblioteca.ibge.gov.br/visualizacao/livros/liv50063.pdf

15 Barros DC, Pereira RA, Gama SGN, Leal MdoC. [Food consumption by pregnant adolescents in Rio de Janeiro, Brazil]. Cad Saude Publica. 2004;20(Suppl 1):S121-S129. Doi: 10.1590/S0102311X2004000700013

16 Chen YC, Huang YC, Lo YC, Wu HJ, Wahlqvist ML, Lee MS Secular trend towards ultra-processed food consumption and expenditure compromises dietary quality among Taiwanese adolescents. Food Nutr Res. 2018;62:1565. Doi: 10.29219/fnr. v62.1565 
17 Roelands J, Jamison MG, Lyerly AD, James AH. Consequences of smoking during pregnancy on maternal health. J Womens Health (Larchmt). 2009;18(06):867-872. Doi: 10.1089/jwh. 2008.1024

18 Freire K, Padilha PdeC, Saunders C. [Factors associated to alcohol and smoking use in pregnancy]. Rev Bras Ginecol Obstet. 2009;31 (07):335-341. Doi: 10.1590/S0100-72032009000700003

19 Leng J, Shao P, Zhang C, Tian H, Zhang F, Zhang S, et al. Prevalence of gestational diabetes mellitus and its risk factors in Chinese pregnant women: a prospective population-based study in Tianjin, China. PLoS One. 2015;10(03):e0121029. Doi: 10.1371/journal.pone. 0121029

20 Lanting CI, Buitendijk SE, Crone MR, Segaar D, Bennebroek Gravenhorst J, van Wouwe JP. Clustering of socioeconomic, behavioural, and neonatal risk factors for infant health in pregnant smokers. PLoS One. 2009;4(12):e8363. Doi: 10.1371/ journal.pone.0008363

21 Kyrklund-Blomberg NB, Granath F, Cnattingius S. Maternal smoking and causes of very preterm birth. Acta Obstet Gynecol Scand. 2005;84(06):572-577. Doi: 10.1111/j.0001-6349.2005.00848.x

22 Beyerlein A, Rückinger S, Toschke AM, Schaffrath Rosario A, von Kries R. Is low birth weight in the causal pathway of the association between maternal smoking in pregnancy and higher BMI in the offspring? Eur J Epidemiol. 2011;26(05):413-420. Doi: 10.1007/s10654-011-9560-y

23 Hackshaw A, Rodeck C, Boniface S. Maternal smoking in pregnancy and birth defects: a systematic review based on 173687 malformed cases and 11.7 million controls. Hum Reprod Update. 2011;17(05): 589-604. Doi: 10.1093/humupd/dmr022

24 Haug K, Irgens LM, Skjaerven R, Markestad T, Baste V, Schreuder P. Maternal smoking and birthweight: effect modification of period, maternal age and paternal smoking. Acta Obstet Gynecol Scand. 2000;79(06):485-489. Doi: 10.1034/j.1600-0412.2000.079006 485. $\mathrm{x}$

25 Suzuki K, Sato M, Zheng W, Shinohara R, Yokomichi H, Yamagata Z. Effect of maternal smoking cessation before and during early pregnancy on fetal and childhood growth. J Epidemiol. 2014;24 (01):60-66. Doi: 10.2188/jea.JE20130083

26 Rogers JM. Tobacco and pregnancy. Reprod Toxicol. 2009;28(02): 152-160. Doi: 10.1016/j.reprotox.2009.03.012
27 Vardavas CI, Chatzi L, Patelarou E, Plana E, Sarri K, Kafatos A, et al. Smoking and smoking cessation during early pregnancy and its effect on adverse pregnancy outcomes and fetal growth. Eur J Pediatr. 2010;169(06):741-748. Doi: 10.1007/s00431-009-1107-9

28 Gennaro S, Biesecker B, Fantasia HC, Nguyen M, Garry D. Nutrition profiles of African [corrected] American women in the third trimester. MCN Am J Matern Child Nurs. 2011;36(02):120-126. Doi: 10.1097/NMC.0b013e3182057a13

29 Pinto RMF, Micheletti FABO, Bernardes LM, Fernandes JMPA, Monteiro GV, Silva MLN, et al. [Female condition of female heads of households in situations of social vulnerability]. Serv Soc Soc. 2011;(105):167-179. Doi: 10.1590/S0101-66282011000100010

30 Ministério da Saúde [Internet]. [Pregnant woman's notebook]. 3rd ed. Brasília (DF): Ministério da Saúde; 2016 [cited 2018 Sep 27]. Available from: https://www.mds.gov.br/webarquivos/arquivo/ crianca_feliz/Treinamento_Multiplicadores_Coordenadores/ Caderneta-Gest-Internet(1).pdf

31 Tomasi E, Fernandes PA, Fischer T, Siqueira FC, Silveira DS, Thumé $\mathrm{E}$, et al. [Quality of prenatal services in primary healthcare in Brazil: indicators and social inequalities]. Cad Saude Publica. 2017;33(03):e00195815. Doi: 10.1590/0102-311X00195815

32 Rios CTF, Vieira NFC. [Educational action in prenatal care: a reflection on nursing consultation as an opportunity for health education]. Cien Saude Colet. 2007;12(02):477-486. Doi: 10.1590/S141381232007000200024

33 Verbeke W, De Bourdeaudhuij I. Dietary behaviour of pregnant versus non-pregnant women. Appetite. 2007;48(01):78-86. Doi: 10.1016/j.appet.2006.07.078

34 Moubarac JC, Martins AP, Claro RM, Levy RB, Cannon G, Monteiro CA; Evidence from Canada. Consumption of ultra-processed foods and likely impact on human health. Public Health Nutr. 2013;16 (12):2240-2248. Doi: 10.1017/ S1368980012005009

35 Yang Q Zhang Z, Gregg EW, Flanders WD, Merritt R, Hu FB. Added sugar intake and cardiovascular diseases mortality among US adults. JAMA Intern Med. 2014;174(04):516-524. Doi: 10.1001/ jamainternmed.2013.13563

36 Louzada MLC, Martins APB, Canella DS, Baraldi LG, Levy RB, Claro $\mathrm{RM}$, et al. Impact of ultra-processed foods on micronutrient content in the Brazilian diet. Rev Saude Publica. 2015;49:45. Doi: 10.1590/S0034-8910.2015049006211 